\title{
Malnutrition Status Among Children in Nepal
}

Poudel Manusha

\begin{abstract}
Malnutrition among children stands as a serious problem to child growth and development and it leads to child morbidity and mortality. This study has tried to find the status of malnutrition among below five years children in Nepal based on the secondary data from Nepal Demographic and Health Survey (NDHS) 2006, 2011 and 2016. Study found out that 36 percent children were stunted in 2016 while 49 percent in 2006. On the other hand wasted has slowly decreased during the ten years period. Results also showed that those mothers who were thin have higher level of stunting, wasting and underweight than those having a normal Body Mass Index (BMI). Study found out that in 2016 more than half children were anemic while the percent was 48 in 2006 and 46 in 2011. To eradicate the level of malnutrition among children and overall development of the country, it is necessary to launch broader platform on nutritional intervention and should be focused at community and region based malnutrition programs.
\end{abstract}

Key words: Child, Malnutrition, Stunted, Wasted, Underweight

\section{Introduction:}

Child Nutritional status is an important concern similar to women and elderly. Child nutrition determines the children's health, physical growth as well as development. Adequate nutrition is essential for decent standard of health. Malnutrition is the state that results from eating a diet in which certain nutrients are lacking, in excess or in the wrong proportion (UNICEF, 2019). It is a type of condition where the body does not get required amount of vitamins, minerals and other nutrients. Globally, malnutrition is more common among under age five years'children and it is a major cause of morbidity and mortality. In Nepal, malnutrition is under-reported, under addressed and as a result under prioritized. Malnourished children are more likely to suffer from diseases; they are physically and intellectually less able or less productive.

Globally, the prevalence of wasting, stunting and underweight is 8 percent, 37 percent and 16 percent respectively. South Asia has the highest prevalence of malnutrition as compared to other regions and the prevalence of wasting, stunting and underweight is 10 percent, 39 percent and 19 percent respectively (WHO, 2016). Now, global nutrition report 2018 says, stunting children has declined and data showed that the percent of underage five stunting children was 32.6 percent in 2000 and it declined 10 percent and reached 22.2 percent in 
2017. In Asia the rate of stunting children in under age five was 38.1 percent in 2000 to 23.2 in 2017 (DI, 2018).

Well nutritious child is crucial for achieving many of the Sustainable Development Goals (SDGs). SDGs 2 said, "End hunger, achieve food security and improved nutrition and promote sustainable agriculture”. It contains five targets: one is end hunger and ensures food access for all, second is to end malnutrition. Third is to double agriculture productivity and income, the fourth is for the food system to be sustainable and fifth is to maintain genetic diversity in both farmed and wild planet (NPC, 2018). For Nepal, National Planning Commission (NPC) proposed for SDGs 2 includes reduction in prevalence of undernourishment (measure of sufficiency of access to food) to 3 percent, prevalence of underweight children aged under five to 5 percent and reduce the prevalence of anemia among children to 9 percent by 2030 (NPC, 2017). In Nepal achieving target two in SDGs 2 will be possible, if the accurate policies and legislation, institutional arrangement and partnership, favorable environment, investment and implementation combined with data monitoring system, are put into place (NPC, 2018).

Malnutrition in children has longterm consequences for national development by perpetuating the cycle of intergenerational poverty and hunger. The data in Nepal showed that it had made progress. For example number of underweight has declined from 39 percent to 27 percent during the period of ten years (2006 to 2016) and percent of stunting children reached 36 in 2016 from 49 in 2006 respectively. For this, the major contribution factors were formulations of several nutritional related policies, presence of NGOs and donor support. But the variations show in gender, ethnic and caste group and socio-economic status.. Despite that, micronutrient deficiency or "hidden hunger" is a pervasive problem in Nepal and it is most commonly caused by poor dietary diversity. Anemia is a major health issue in Nepal especially children and pregnant women. Nepal Demographic and Health Survey data showed that about 53 percent children who are under age five years are anemic in Nepal (NPC, 2018).

\section{Methodology}

This paper has tried to find the status of malnutrition among below five years children in Nepal. More specifically it has explored the levels and trends of malnutrition since 2006. This study is based on the secondary data from Nepal Demographic and Health Survey 2006, 2011 and 2016. Stunting, wasting, underweight and some associated factors of nutritional status were major displays to measure the malnutrition in this study. 


\section{Results and Discussions}

According to the WHO, "Malnutrition refers to deficiencies, excesses, or imbalances in a person's intake of energy and / or nutrients." The term malnutrition addresses three broad groups of conditions: they are under-nutrition, micronutrient related malnutrition and overweight/ obesity (MoHP, 2008). This paper has tried to display under-nutrition in focus center and touch rest of others.

Table 1: Trend and Distribution of Stunted, Wasted and Under-weight Children in Under Five Year's Age

\begin{tabular}{|l|l|l|l|}
\hline Indices & $2006(\%)$ & $2011(\%)$ & $2016(\%)$ \\
\hline Stunted & 49 & 41 & 36 \\
\hline Severely Stunted & 20 & 16 & 12 \\
\hline Wasted & 13 & 11 & 10 \\
\hline Severely Wasted & 3 & 3 & 2 \\
\hline Underweight & 39 & 29 & 27 \\
\hline Severely Underweight & 11 & 8 & 5 \\
\hline
\end{tabular}

Source: Nepal Demographic and Health Survey, 2006, 2011 and 2016.

The status of stunted children in Nepal has improved over the past 10 years. In 2006, around half of the under-five year's children were stunted whereas in 2016 nearly one third is stunted. Similarly, underweight percent has also improved well during this period. Despite that, the wasted has decreased only 3 during 10 years period and reached in 10 percent.

\section{Stunted (Height for age)}

Stunted reflects failure to receive adequate nutrition over a long period of time and is affected by recurrent and chronic illness. Therefore, stunted (height for age) represents the long term effects of malnutrition in a population and is not sensitive to recent, short term changes in dietary intake.

Table 2: Trend and Pattern of Stunted Children in Under Five Years Age by Background Characteristics

\begin{tabular}{|l|l|l|l|}
\hline \multirow{2}{*}{ Background Characteristics } & \multicolumn{3}{|l|}{ Stunted } \\
\cline { 2 - 4 } & $\mathbf{2 0 0 6} \mathbf{( \% )}$ & $\mathbf{2 0 1 1}(\mathbf{\% )}$ & $\mathbf{2 0 1 6} \mathbf{( \% )}$ \\
\hline Sex & & & \\
\hline Male & 49.0 & 41.4 & 36.0 \\
\hline Female & 49.6 & 39.5 & 35.7 \\
\hline Mother's Nutritional Status & & & \\
\hline Thin (BMI<18.5) & 54.7 & 47.0 & 45.4 \\
\hline
\end{tabular}




\begin{tabular}{|l|l|l|l|}
\hline Normal (BMI18.5-24.9) & 49.1 & 40.0 & 36.3 \\
\hline Overweight (BMI>=25) & 27.8 & 27.2 & 23.9 \\
\hline Residence & & & \\
\hline Urban & 36.1 & 26.7 & 32.0 \\
\hline Rural & 51.1 & 41.8 & 40.2 \\
\hline Ecological Zones & & & \\
\hline Mountain & 62.3 & 52.9 & 46.8 \\
\hline Hill & 50.3 & 42.1 & 32.3 \\
\hline Terai & 46.3 & 37.4 & 36.7 \\
\hline Mother's Education & & & \\
\hline No Education & 57.7 & 47.6 & 45.7 \\
\hline Primary & 46.3 & 40.6 & 36.7 \\
\hline Some Secondary & 29.7 & 32.0 & 31.5 \\
\hline SLC and above & 15.6 & 25.6 & 22.7 \\
\hline Wealth Quintile & & & \\
\hline Lowest & 61.6 & 56.0 & 49.2 \\
\hline Second & 54.9 & 45.7 & 38.7 \\
\hline Middle & 50.4 & 34.5 & 35.7 \\
\hline Fourth & 39.8 & 30.5 & 32.4 \\
\hline Highest & 30.9 & 25.8 & 16.5 \\
\hline
\end{tabular}

Source: Nepal Demographic and Health Survey, 2006, 2011 and 2016.

Above table (Table 2) shows that the percent of stunted has not much different among male and female children since 2006. Table displays that children have higher level of stunting whose mothers are thin compared with those mothers having normal Body Mass Index (BMI). Similarly, two fifth rural children have stunted whereas in urban areas around one third children have stunted in 2016. In addition, mountain region has the highest proportion of children who are stunted (47\%) in 2016 and in 2006 the rate was 62 percent. Similarly, table shows that education plays a crucial role to be stunted, those mothers who have no education has higher stunted rate (46\%) than SLC and above (23\%). Stunted is relatively high among children from the lowest wealth quintile (49\%) compared with the highest wealth quintile (17\%) and we can see the similar pattern in 2006 and 2011.

Table also prevails that, the prevalence of stunted children under age five years have noticeably decreased and we can observed the downward trend. On the other hand, there is a wide variation in rates of stunted throughout Nepal by ecological, residence, education and wealth quintile. 


\section{Wasted (Weight for Height)}

Wasted represents the failure to receive adequate nutrition in the period immediately preceding the survey and may be the result of inadequate food intake or a recent episode of illness causing loss of weight and the onset of malnutrition.

Table 3: Trend and Pattern of Wasted Children in Under Five Years by Background Characteristics

\begin{tabular}{|l|l|l|l|}
\hline \multirow{2}{*}{ Background Characteristics } & Wasted & $\mathbf{2 0 1 6}(\%)$ \\
\cline { 2 - 4 } & $\mathbf{2 0 0 6} \mathbf{( \% )}$ & $\mathbf{2 0 1 1}(\mathbf{\% )}$ & \\
\hline Sex & & & 9.5 \\
\hline Male & 12.9 & 12.0 & 9.8 \\
\hline Female & 12.3 & 9.7 & \\
\hline Mother's Nutritional Status & & & 14.9 \\
\hline Thin (BMI<18.5) & 22.0 & 18.9 & 9.9 \\
\hline Normal (BMI18.5-24.9) & 10.2 & 9.2 & 4.9 \\
\hline Overweight (BMI>=25) & 3.1 & 7.0 & \\
\hline Residence & & & 9.2 \\
\hline Urban & 7.5 & 8.2 & 10.2 \\
\hline Rural & 13.3 & 11.2 & \\
\hline Ecological Zones & & & 6.1 \\
\hline Mountain & 9.4 & 10.9 & 6.4 \\
\hline Hill & 8.4 & 10.6 & 12.2 \\
\hline Terai & 16.6 & 11.2 & \\
\hline Mother's Education & & & 12.5 \\
\hline No Education & 14.7 & 13.3 & 9.0 \\
\hline Primary & 8.4 & 11.3 & 8.8 \\
\hline Some Secondary & 11.4 & 5.5 & 7.5 \\
\hline SLC and above & 7.7 & 9.7 & \\
\hline Wealth Quintile & & & 8.8 \\
\hline Lowest & 11.5 & 12.5 & 9.4 \\
\hline Second & 15.2 & 10.7 & 10.6 \\
\hline Middle & 15.2 & 12.8 & 11.3 \\
\hline Fourth & 12.8 & 8.8 & 7.3 \\
\hline Highest & 7.0 & 7.4 & \\
\hline
\end{tabular}

Source: Nepal Demographic and Health Survey, 2006, 2011 and 2016.

Above table (Table 3) shows that wasting has fallen slowly. In overall, it has fallen from 13 percent in 2006 to 10 percent in 2016. The variation in the prevalence of wasting can be seen in gender, place of residence, regions, education and wealth. Wasting is 9.8 percent in females compared to 9.5 percent in males, here is only little different. Table shows that, children have higher level of wasting among thin mothers (15\%) compared with normal (10\%) and table also shows the same pattern and high variations in 2006 and 2011 data. 
Similarly, wasting is slightly higher in rural areas (10\%) compared to urban ones (9\%). Likewise, ecological zones, education of mother and wealth quintile play a vital role to fluctuate the percent of wasting. Like in stunting, wasting percent is higher in uneducated mothers than who crossed SLC and above. Despite that, the trend of wasting percent on SLC and above has nearly constant.In 2006, the wasting percent on SLC and above was 7.7 percent and in 2016 it is 7.5 percent only.

Despite that, table shows slightly different in wealth quintile category. Middle and fourth wealth quintile have highest wasting (11\% and $13 \%$ respectively) than lowest wealth quintile (9\%). Similarly, children who have highest wealth quintile, have low percent of wasting (7\%) shows the 2016 data.

\section{Underweight (Weight for age)}

Weight for age is a composite index of height for age and weight for height. It takes into account both chronic and acute malnutrition.

Table 4: Trends and Patterns of Underweight Children in Under Five Years by Background Characteristics

\begin{tabular}{|l|l|l|l|}
\hline \multirow{2}{*}{ Background Characteristics } & \multicolumn{3}{|l|}{ Underweight } \\
\cline { 2 - 4 } & $\mathbf{2 0 0 6}(\mathbf{\% )}$ & $\mathbf{2 0 1 1}(\mathbf{\% )}$ & $\mathbf{2 0 1 6}(\mathbf{\% )}$ \\
\hline Sex & & & \\
\hline Male & 37.5 & 29.6 & 26.7 \\
\hline Female & 39.7 & 28.6 & 27.4 \\
\hline Mother's Nutritional Status & & & \\
\hline Thin (BMI<18.5) & 54.4 & 40.1 & 43.1 \\
\hline Normal (BMI18.5-24.9) & 35.2 & 27.5 & 26.7 \\
\hline Overweight (BMI>=25) & 9.3 & 12.6 & 11.0 \\
\hline Residence & & & \\
\hline Urban & 23.1 & 16.5 & 23.4 \\
\hline Rural & 40.7 & 30.0 & 31.1 \\
\hline Ecological Zones & & & \\
\hline Mountain & 42.4 & 35.9 & 28.5 \\
\hline Hill & 33.2 & 26.6 & 18.1 \\
\hline Terai & 42.3 & 29.5 & 32.5 \\
\hline Mother's Education & & & \\
\hline No Education & 46.6 & 38.4 & 36.7 \\
\hline Primary & 31.1 & 26.1 & 28.0 \\
\hline Some Secondary & 24.0 & 18.8 & 16.1 \\
\hline SLC and above & 11.0 & 13.3 & \\
\hline & & & \\
\hline
\end{tabular}




\begin{tabular}{|l|l|l|l|}
\hline Wealth Quintile & & & \\
\hline Lowest & 47.0 & 40.3 & 32.9 \\
\hline Second & 46.0 & 31.6 & 28.3 \\
\hline Middle & 41.7 & 28.8 & 32.8 \\
\hline Fourth & 31.0 & 22.9 & 23.5 \\
\hline Highest & 18.8 & 10.0 & 11.6 \\
\hline
\end{tabular}

Source: Nepal Demographic and Health Survey, 2006, 2011 and 2016.

Table 4 shows the downward trend in underweight children from 2006 to 2016. The variations found by different characteristics. High variations found in Mother's nutritional status. Mothers who are thin have higher percent of underweight children (43\%) than normal (27\%). Similar pattern seen in 2006 data, it showed that whose mother were thin, had more than half (54\%) under five children were underweight. Similarly, rural areas children have higher percent of stunted (31\%) than urban (23\%) in 2016. Similar pattern had seen in 2006 and 2011 data. Differently, in geographical regions, data found that children who stayed in terai region have higher percent of underweight (33\%) than mountain (29\%) and hill (18\%). But 2011 and 2006 data showed that mountain region had higher percent of underweight (36\% in 2011 and 42\% in 2006) than terai and hilly regions.

Additionally, education level of mother determines the level of underweight children. With increasing level of education of mother, has decreasing the underweight percent. The same pattern stayed in 2006 and 2011 data. Data 2016 showed that mother who have no education have higher (37\%) percent of underweight children than SLC and above (16\%) education of mother. Likewise, who has lowest wealth quintile have higher percent of underweight children (33\%) and who has highest wealth quintile have lower number of underweight (12\%) children in 2016. The same pattern had remained in 2006, and 2011 data.

\section{Associated Factors of malnutrition}

Breastfeeding is an associated component of infant and young child feeding practices which is directly linked with malnutrition. Breastfeeding is nearly universal in Nepal, 99\% children have been breastfed at some time (NDHS, 2016).

Table 5: Trend of Breastfeeding, Exclusive Breastfeeding and Other Nutritional Status among Under Age 5 Years Children

\begin{tabular}{|l|l|l|l|}
\hline Associated indicators of child nutritional status & 2006 NDHS & 2011NDHS & 2016NDHS \\
\hline Breastfeeding within one hour & $35 \%$ & $45 \%$ & $55 \%$ \\
\hline Exclusive breastfeeding under six months & $53 \%$ & $70 \%$ & $66 \%$ \\
\hline $\begin{array}{l}\text { Prevalence of breastfed children 6-23 months } \\
\text { receiving minimum acceptable diet }\end{array}$ & $57 \%$ & $24 \%$ & $36 \%$ \\
\hline
\end{tabular}




\begin{tabular}{|l|l|l|l|}
\hline $\begin{array}{l}\text { Coverage of vitamin A supplements for } \\
\text { children (6-59 months) }\end{array}$ & $88 \%$ & $90 \%$ & $86 \%$ \\
\hline $\begin{array}{l}\text { Percentage of children 6-59 months living in } \\
\text { households with iodized salt }\end{array}$ & - & $73 \%$ & $95 \%$ \\
\hline
\end{tabular}

Source: Nepal Demographic and Health Survey, 2006, 2011 and 2016.

Table 5 shows the influencing factors of children's nutritional status. It shows, more than half of the children, only 55 percent are breastfed within hour of birth in 2016 and it has increased from more than one third, 35 percent in 2006. Thought the percent is less. The prevalence of exclusive breastfeeding overallhas declined from 70 percent in 2011 to 66 percent in 2016.

Micronutrient deficiency or "hidden hunger" is a widespread problem in Nepal and it is most commonly caused by poor dietary diversity. In Nepal, complementary feeding practices are poor, only 36 percent of breastfed children 6-23 months receiving a minimum acceptable diet and in 2006 this rate was 57 percent. Similarly, vitamin A is an essential micronutrient for the immune system and plays an important role in maintaining the epithelial tissue of the body. Severe vitamin A deficiency can cause eye damage, childhood blindness and lowered immunity. Table shows that majority of children (86\%) cover vitamin A supplements for children. In Nepal, over the past 20 years, has been carrying out a semi- annual high dose vitamin A capsule supplementation campaign for children age 659 months together with distribution of deworming tablets for children age 12- 59 months. But the consumption of vitamin A reach food among children 6-23 months is 63 percent in 2016. This shows that vitamin A deficiency may still be an issue, particularly among children 6-59 months. Finally, due to iodized salt policy (95\%), it has become less concern in Nepal.

Anemia is another major health issue in Nepal especially children and pregnant women. It is a serious concern for children because it weakens the cognitive development and long term health and economic consequences. Severe anemia leads to increase mortality. The most common cause of anemia is inadequate dietary intake of nutrients necessary for synthesis of hemoglobin, such as iron, folic acid and vitamin B12.

When we look the situation of anemia in Nepal, it remains a widespread problem and it has been increasing from 46 percent in 2011 to 53 percent in 2016 among children 6-59 months. One more concerning is that 69 percent children aged 6 to 23 months suffer from anemia which is unchanged since 2006.

Table 6: Trend and Distribution of Anemia among UnderAge 5 Years children (based on hemoglobin level)

\begin{tabular}{|l|l|l|l|l|}
\hline Surveys & $\begin{array}{l}\text { Any } \\
(<11.0 \mathrm{~g} / \mathrm{dl})\end{array}$ & $\begin{array}{l}\text { Mild } \\
(\mathbf{1 0 . 0 - 1 0 . 9} \mathrm{g} / \mathrm{dl})\end{array}$ & $\begin{array}{l}\text { Moderate } \\
(\mathbf{7 . 0 - 7 . 9} \mathrm{g} / \mathrm{dl})\end{array}$ & $\begin{array}{l}\text { Severe } \\
(<7.0 \mathrm{~g} / \mathrm{dl})\end{array}$ \\
\hline
\end{tabular}




\begin{tabular}{|l|l|l|l|l|}
\hline NDHS 2006 & 48.4 & 26.4 & 21.7 & 0.6 \\
\hline NDHS 2011 & 46.2 & 27.4 & 18.3 & 0.5 \\
\hline NDHS 2016 & 52.7 & 26.2 & 26.0 & 0.5 \\
\hline
\end{tabular}

Source: Nepal Demographic and Health Survey, 2006, 2011 and 2016.

Table 6 prevails that, about 53 percent of under aged five years children are anemic in Nepal and among them, 26 percent mildly, 26 percent moderately and 1 percent severely anemic while in 2006 the any anemia rate was nearly half and in case of severe it is around constant since 2006 which is one of the leading factor of childhood mortality.

Table 7: Trend and Pattern of anemia status among Under 5 Children by Background Characteristics (Based on Hemoglobin Level)

\begin{tabular}{|c|c|c|c|}
\hline \multirow{2}{*}{ Background Characteristics } & \multicolumn{2}{|l|}{ Any Anemia } & \multirow{2}{*}{ NDHS 2016} \\
\hline & NDHS 2006 & NDHS 2011 & \\
\hline \multicolumn{4}{|l|}{ Sex } \\
\hline Male & 48.1 & 43.4 & 52.7 \\
\hline Female & 48.6 & 49.1 & 52.6 \\
\hline \multicolumn{4}{|l|}{ Deworming Status } \\
\hline Receive deworming medication* & 42.6 & 41.3 & 44.8 \\
\hline Not receive deworming medication* & 52.3 & 50.6 & 57.1 \\
\hline \multicolumn{4}{|l|}{ Residence } \\
\hline Urban & 41.1 & 41.2 & 49.3 \\
\hline Rural & 49.3 & 46.7 & 56.3 \\
\hline \multicolumn{4}{|l|}{ Ecological zones } \\
\hline Mountain & 45.2 & 47.7 & 57.4 \\
\hline Hill & 36.9 & 41.0 & 40.1 \\
\hline Terai & 58.3 & 50.2 & 60.0 \\
\hline \multicolumn{4}{|l|}{ Mother's Education } \\
\hline No education & 51.8 & 50.1 & 56.9 \\
\hline Primary & 45.2 & 42.6 & 52.7 \\
\hline Some Secondary & 44.2 & 42.8 & 52.5 \\
\hline SLC and above & 42.9 & 43.3 & 44.1 \\
\hline \multicolumn{4}{|l|}{ Wealth Quantile } \\
\hline Lowest & 47.6 & 45.3 & 48.7 \\
\hline Second & 51.6 & 49.6 & 49.6 \\
\hline Middle & 53.7 & 51.4 & 59.9 \\
\hline Fourth & 47.0 & 43.3 & 58.4 \\
\hline Highest & 39.3 & 37.5 & 41.2 \\
\hline Total & 48.4 & 46.2 & 52.7 \\
\hline
\end{tabular}


Source: Nepal Demographic and Health Survey, 2006, 2011 and 2016.

Table 7 shows the trends of anemia among children under aged five years by background characteristics. It shows that children who have used deworming medication have lower prevalence of anemia (45\%) than who have not used deworming medication (57\%). Prevalence has been increasing since 2006. Similarly, children who have stayed in rural areas have higher percent of anemia (56\%) than urban (49\%). Likewise, in terai region has highest prevalence of anemia (60\%) than mountain (56\%) and hill (40\%). Additionally, those mothers who have no education have higher prevalence of anemia (57\%) than SLC and above (44\%). Children who have middle wealth quintile have higher prevalence of anemia (60\%) which was unchanged ranked since 2006.

\section{Discussions}

The nutritional status of children in Nepal has improved over the past 15 years. The findings of Nepal Multiple Indicator Cluster Survey (NMICS) 2016 shows, the stunting percent was 37, whereas wasting and underweight were 11 and 30 percent respectively (DOHS, 2016). This shows the similar result (slightly decrease) in NDHS 2016. Despite that, another study which was conducted in three districts (Lamgung, Tanahu and Gorkha) of hilly region found that the prevalence of stunting was $54 \%$, wasting was $11 \%$ and underweight was $21 \%$ among under five years children. It shows the wide variations by districts and geographical regions in stunting and underweight children (Dhungana G, 2017). South Asia has the highest prevalence of malnutrition than other region, the 2018 global nutrition report shows that 23 percent children from birth to 59 months have stunted (IFPR, 2016) which was lower than Nepal (36\%). It shows that still Nepal remains in high prevalence in south Asia.

Additionally, to address the associated elements of malnutrition, breast milk is major one. First breast milk contains colostrum, which is highly nutritious and contains antibodies to protect the newborn from disease. Early initiation of breastfeeding also encourages boding between mother and child facilitating the production of regular and adequate breast milk. So that, it is recommended to children to feed breast milk immediately or within one hour after birth and the pre lacteal feeding be discouraged. While in Nepal, only 55\% children have breastfed within one hour of birth. Besides that, complementary feeding practices is not good in Nepal and the prevalence of anemia is also increasing trend.

\section{Conclusion}

In Nepal, malnutrition remains as a serious concern to child survival, growth and development. The overall prevalence of stunting is higher as compared to wasting and underweight. Residence, ecological variations and mother's education and nutritional status remain great concern in Nepal. Additionally, less number of breastfeeding within one hour and exclusive breastfeeding hinder to decrease the level of malnutrition. Similarly, poor 
percent of consumption of minimum acceptable diet and increasing level of anemia among children affect the well nutritional status among children and targets to reach the SDGs 2. To address this issue, it is necessary to introduce broader package of nutritional intervention specifically community and region based by the means of counseling and education. Breastfeeding, complementary breastfeeding, anemia, vitamin A reach foods must be addressed. Finally, Poverty reduction strategy and programs could also serve as long term solution to the problem.

\section{References:}

Department of Health Services.(2016). Annual Report 2014/2015.Ministry of Health, Government of Nepal, Kathmandu, Nepal.

Development Initiatives (DI).(2018). Global Nutrition Report: Shining a Light to Spur Action on Nutrition. Bristol, UK: Development Initiative.

Dhungana, G.(2017).Nutritional Status and Associated factors in Under Five Years Children of Lamjung, Gorkha and Tanahu Districts of Nepal. Nepalese Journal of Statistics, Vol 1, 15-28.

International Food Policy Research Institute (IFPR). (2016). Global Nutrition Report 2016: From Promise to Impact: Ending Malnutrition by 2030. Washington DC.

Ministry of Health and Population (MoHP) [Nepal], New ERA and ICF International.(2017). Nepal Demographic and Health Survey 2016. Kathmandu, Nepal: Ministry of Health and Population, New ERA, and ICF International.

Ministry of Health and Population (MoHP) [Nepal], New ERA and ICF International.(2012). Nepal Demographic and Health Survey 2011. Kathmandu, Nepal: Ministry of Health and Population, New ERA, and ICF International.

Ministry of Health and Population (MoHP) [Nepal], New ERA and ICF International.(2006). Nepal Demographic and Health Survey 2006. Kathmandu, Nepal: Ministry of Health and Population, New ERA, and ICF International.

Ministry of Health and Population.(2008). National Nutrition Policy and Strategy.Government of Nepal.Ministry of Helath and Population, Kathmandu Nepal.

National Planning Commission (NPC).(2017). Nepal Sustainable Development Goals.Baseline Report, 2017.Government of Nepal.National Planning Commission Kathmandu, Nepal.

National Planning Commission (NPC).(2018). Towards Zero Hunger in Nepal.A strategic Review of Food, Security and Nutrition, 2018.National Planning commission, Kathmandu, Nepal.

UNICEF.(2019). The State of the World's Children 2019. Children, Food and Nutrition: Growing Well in Chinging World. UNICEF, New York.

WHO, UNICEF and World Bank.(2016). Levels and Trends in Child Malnutrition.UNICEF/ WHO/ World Bank Group.Joint Child Malnutrition Estimates.Key Findings of the 2016 Edition. 